\title{
IMPACT OF INFORMATION TECHNOLOGY AND DIGITALIZATION ON BANKING STRATEGY PRE-COVID- 19, CHALLENGES IN THE COVID ERA AND POST-COVID STAKES
}

\author{
Syrine Ben Romdhane \\ Assistant Professor \\ High Institute of Management of Tunis \\ University of Tunis, Tunisia \\ E-mail: srnbenromdhane@gmail.com
}

\begin{abstract}
The spread of information technology and the digitalization of financial services raise a range of theoretical questions as the structures of the banking industry undergo change. This change has intensified with the impact of the COVID-19 pandemic which is already being observed. The purpose of this study is therefore threefold: (1) to analyze the impact of IT and the digitalization of financial services on the strategy and functioning of the pre-COVID-19 banking sector; (2) to study the challenges banks are facing in the COVID era in managing the crisis, and (3) to highlight post-COVID stakes. This study shows, on the one hand, that the crisis confirms the need for banks to combine physical proximity and digital offer, and on the other hand, that digitalization could be the solution for banks to consistently mitigate risks. Through this digital transformation and their ability to re-invent themselves, the banks would guard against potential similar crises. By adopting a more digitized and open behavior, they would be immune to such crises because they would have appropriate strategic plans, as they would be better equipped to counter the threats and better prepared to transform them into opportunities.
\end{abstract}

Keywords: Information Technology, Digitalization, Strategy, Banks, COVID-19.

JEL Classification Codes: B26, B41, G21, G32, O32.

\section{INTRODUCTION}

According to Roman and Tchibozo (2017), there is hardly any other profession that is the object of as much analysis, attention and fear as banking. Caught in the midst of the financial turmoil of 2008 and 2011, saved and placed under trusteeship, considerably weakened yet essential to the entire economic and financial fabric, strengthened but shaken, the banking industry will have to renew itself tomorrow and undergo fundamental changes in order to exist. To undertake this transformation, banks are developing intentions and initiatives to carry out their activities successfully and come out victorious and strengthened from the current movement, especially in a context where the COVID-19 pandemic reigns. This unprecedented crisis resulting from the coronavirus highlighted the essential role played by digital technologies.

Indeed, information systems in general and digital technologies in particular represent an invaluable solution. Today, they are essential to the competitiveness of banks, and managers need to understand and master their essential mechanisms (Ben Romdhane, 2016). 
They need to know what they are, how they influence the organization, how they can improve earnings and how to make the bank more efficient. The information system is an asset in business competition. Its robustness and reliability are as important as its performance and quality of service to customers.

The spread of information technology (IT) and the digital transformation of financial services raise a series of theoretical considerations. Many questions arise as the structures of the banking industry are modified. According to the three-pronged approach to the industrial economy, structure-behavior-performance, the structures of an industry is dependent on the behavior of the firms from which performance is derived. The deregulation of the banking industry and the evolution of banking demand and supply have generated a trend that accelerates this dissemination process within the industry. This trend has intensified with the effects of the COVID-19 pandemic which are already being felt. The objective of this study is therefore to analyze the impact of IT and the digitalization of financial services on the strategy and operation of the pre-COVID-19 banking sector. We will then consider the challenges that banks face in the COVID era to manage the crisis as well as post-COVID issues.

Thus, in order to understand this IT integration process in the banking industry, it is necessary to first examine IT in the technology development of banking and define the waves of technological innovations introduced in banks since 1845 and their evolution up to the digitization of banking services, or even their digitalization. We will then present the preCOVID-19 transformations resulting from this IT dissemination and digitalization at the level of banks' strategies, and particularly their impacts on organizational, commercial and financial performance. Finally, we will consider the challenges of banking business models in the COVID-19 era and the stakes to be met by post-COVID banks, the latter being dependent on the environmental context in which they operate.

\section{INFORMATION TECHNOLOGY IN THE BANKING TECHNOLOGICAL TREND}

Thanks to innovation, a new world is born characterized by waves of technological innovations and by the emergence of new products and new structures. Faced with these changes, consumer preferences are changing and companies no longer produce to sell but to satisfy them. To understand the upheavals in the banking sector, it is necessary to study the context in which these changes are taking place. The objective of this first section is therefore to analyze the momentum in which this process is taking place.

\section{The Waves of Technological Innovation in the Banking Industry (1845-2002)}

In what follows, we present the different waves of technological innovation in banking between the 1845 and 2002, as outlined by Morris (1986) and Quintas (1991).

\section{The First Wave of Technological Innovations}

This first wave began in 1846 when the telegraph was first used by the banking industry. This first wave of technological innovation only had a limited effect on "front-office" procedures. It mainly concerned internal changes since transactions between the banking institution and the client remained unchanged and a single channel was used: the branch. At the beginning of the century, back-office functions were limited to processing checks and drawing up balance sheets of cash transactions. And as the volume of financial transactions increased, the need for mechanization arose. The introduction of numerous machines at the back-office level improved the working conditions of the employees and contributed to increased productivity in the branches. The use of these machines was not really effective until the 1950s, which explains the phenomenon of the extension of branch networks. These changes led to the emergence of numerous performance indicators that measure growth in size based on revenue per employee, transaction efficiency i.e. profitability and credit-related risks. 


\section{The Second Wave of Technological Innovations}

This second wave began in the late fifties and lasted until the end of the eighties. It was marked by the introduction of IT in the financial sector to cope with the growth in transaction volumes. The first experiences with the use of IT in banking took place in 1984 in the United States. This period was characterized by a significant dissemination of hardware but much less so of software. During this phase, the primary objective of financial institutions was to reduce the costs of administrative tasks resulting mainly from check processing. The idea therefore stemmed from a desire to automate transactions at the branch level. Thus, at the beginning of the sixties, the large American and English banks witnessed the arrival and installation of their first computer systems. The introduction of information technology in this sector favored a greater automation of administrative tasks, which in turn favored an enhanced centralization of decision-making in the banking sector, leading to a standardization of the offered services.

\section{The Third Wave of Technological Innovations}

It was during this period that banks became the first consumers of computer applications that far outperformed other sectors such as transportation, manufacturing, etc. The service market was often seen as a non-dynamic sector with zero or low productivity and struggling to innovate. From this period onwards, investments in information technology steadily increased. However, this growth has taken place with disparities between countries, which in the long term contributed to increasing the gaps between developed and less developed countries.

This period is mainly characterized by important developments in software. It was during this period that applications such as "Electronic Data Interchange EDI" - a network that allows payment transfers between banks- were born. This technology was the catalyst for the development of significant economies of scale and cost savings. This period was also distinguished by the complete automation of branch transactions, thus reducing the time and cost of an operation. This surge in automation allowed easier control of the various agencies by the central office. This wave also marked the birth of electronic banking.

This phase differs from the two previous phases in that the innovations are both internal and external. Internal, by the extent of the productivity gains fostered by the development of EDI, and external, by the rapid growth of the ATM network in various developed countries. The ATM network development was therefore the first innovation at the level of the bank-customer relationship. This innovation changed the way, place and time at which customers can contact their bank. It is this phase that allowed a convergence of telecommunications and computer technology, which gave birth to the term "information technology". However, this phase remained dominated by an internal rationale for banks, namely cost reduction.

\section{The Fourth Wave of Technological Innovations}

The development of the Internet, and in particular online banking, is at the heart of the fourth wave of technological innovation, the "dissemination" phase. This wave is characterized by the acceleration of the transmission of information flows, the reduction of costs and the increase in the distance over which information can be transmitted. In practice, these changes have led to the development of information processing methods in the banking sector, as well as a multiplication of distribution channels, a growing interest in integrating technologies into products and particularly the development of electronic payment methods. At the beginning of this phase, the banks started by developing databases (data warehouse) gathering information about their customers, a method that allowed them to save a considerable amount of time. Indeed, knowing the qualities of a customer takes only three to four weeks, whereas it used to 
take more than five years. In parallel with the development of information processing, significant progress has also been made in the area of communication. This fourth wave of innovations is very marked by changes in customer behavior, particularly in their choice of distribution channels.

As a result, developments in computer and network technologies have enabled the Internet to become a real account management channel. Internet banking, unlike other distribution channels, allows greater customization of messages. It allows customers to download data, personal financial management software, but also to place stock market orders in real time. The introduction of the Internet in the financial sector today is a revolution in itself.

Reix (1998) identifies six essential elements of Internet services. First, electronic messaging, which allows written messages to be sent between users with an e-mail address. Second, tele-connection to other computers on the network for remote processing. Third, the transfer of large files from computer to computer. Fourth, electronic forums, a thematic discussion forum where everyone can contribute. Fifth, menu-guided browsing, which makes it possible to search documents on various topics in databases located around the world. Sixth, the World Wide Web, which allows browsing between the different sites of the network, without having to know their addresses thanks to hypertext links. Many of these features can help improve information management in the bank, especially since the network is not static. In fact, the Internet is not a network coordinated by a predefined manager, but a set of networks that are coordinated through the use of a common TCP/IP communication protocol between the different computers. This protocol favors the interconnection of the large networks that existed previously and explains the dramatic growth of the Internet, which in 1997 had more than fifteen million connected computers and about eighty million users (Lahittete, 1999). The Internet is thus a hierarchy of interconnected networks linking banks, financial institutions and customers.

\section{Banking Services in the Digital Age: Digital Transformation}

Already established and adopted for several years in the private sphere, digital technology is not a revolution for companies, but a natural evolution. As far as the banking sector is concerned, the difficulties faced by stakeholders are more cyclical than structural. With the recurring crises of recent years, banks were reluctant to invest in digital development or to launch projects to overhaul information systems. However, a number of them are initiating a digital shift with the emergence of corporate social networks and MOOCs (online training open to all) or even allowing employees to use their personal devices and equipment. At a time when information flows freely without interruption and access to multiple services is facilitated through the Internet, bank customers are becoming demanding and expect a certain continuity of service and more interaction.

In the banking sector, the "digital" transition has already been underway for several decades, first with the generalization of call centers (allowing for greater availability of telephone assistants), then with the creation of branches (online branches offering almost the same services as a physical branch), or more recently with the appearance of mobile banking applications. Indeed, digital banks have a mobile-centric approach: it is above all through the application on the smartphone that customers will be able to manage their accounts online. Not only can they check their account via the digital bank, but also perform all daily banking operations such as adding a recipient or making a transfer. New features have also been introduced. Among them, the categorization of expenses, the reception of text messages on account balances, the display of information feed with the latest payments, etc. All these possibilities bring a new way of consuming banking products: immediacy, highly visual presentation and information. Young people, in particular, appreciate these features to which 
they have become accustomed with smartphones and applications. To cope with this trend, traditional banks are also striving to go digital.

\section{IT AND DIGITAL TRANSFORMATION CONTRIBUTIONS TO PRE-COVID-19 BANKING}

The adoption of IT in banks and financial institutions and the digitization of their services have today become a necessity rather than a choice. Indeed, these technologies are essential tools that banking institutions must manage and master to ensure their competitiveness. They have been integrated into the productive system of banks following the emergence of new equipment and the evolution of their needs.

\section{Impact of IT on Organizational, Commercial and Financial Performance of Banks}

Information technologies play an important role in the company, and in this specific case, the bank. They are now crucial because of the scale of the changes they entail in the production process: acceleration of productivity gains, upheaval of the banks' organizational structure, reengineering, i.e. reorganization of banks into more flexible units, emergence of new distribution channels, etc. They also play an important role in banks' development strategies. It is therefore relevant to analyze how banking institutions react in their organization but also in their operating mode to the introduction of these IT.

According to Porter (1980) and Porter and Millar (1985), the impact of IT on banking performance is multidimensional and provides competitive advantages to banks. Indeed, according to these authors, this impact may include a reduction in costs, innovation, improved negotiating and anticipatory power of managers, and the development of distinctive skills. As in many other sectors, the advent of the Internet in financial services seemed to materialize in a form of battle between two opposing sides: on the attack side, the new entrants with assets that would allow them to remove a growing number of access barriers. On the defense side, the established institutions that perceived the Internet revolution as a threat: loss of markets, disappearance of intermediation functions... As a result, these institutions needed to implement organizational innovations in order to remain competitive.

\section{Far-Reaching Organizational Changes}

IT adoption drives organizational innovation (Selase \& Selase, 2019). Indeed, their dissemination in banks leads to many organizational changes because they play a significant role in the development strategies of banks. The combination of a number of factors: IT adoption, increased competition, and the advent of virtual entrants have prompted traditional banks to reorganize. This reorganization is performed in two different but complementary directions: a micro-economic type of reorganization that focuses on the internal evolution of banks, and another meso-economic one that focuses on the strategic evolution of banks. Following the major transformation of the bank's internal organization and its relationships with its external partners, IT investments offer new organizational models and new bank/client relationships. The spread of IT and especially the Internet means that banks need to make organizational innovations in order to remain competitive.

According to Venkatraman (1995), the organizational consequences of introducing IT for the bank may initially take the form of strategic changes in the redesign of internal transaction management processes and the adoption of new management methods, the redefinition of organizational charts, the management of service quality issues, and even the reformulation of the bank's objectives and business portfolio. Indeed, Laudon and Laudon (2006) developed a theory according to which IT makes it possible to flatten hierarchies by broadening the distribution of information, which empowers employees at lower levels and improves management efficiency. Since operational managers receive this information 
directly and more quickly, they can intervene directly and in a timely manner. As a result, the organization needs fewer middle managers dedicated to the sole transmission of providing instructions and information (Drucker, 1988; Brynjolfsson \& Hitt, 2000; Malone, 1997). In addition, the development of IT and the increase in internal and external competition in the industry are prompting banks to reflect on their entire activities, i.e. their value chain. The weight of these activities varies from one banking firm to another. Lemarque (1999) points out that risk management and distribution appear to be the key activities of the value chain.

Risk management is a strategic activity involving the selection of clients and operations that condition the profitability of credit. Distribution is also a source of competitive advantage. Today, IT development offers banking firms the opportunity to reformulate their objectives as well as their business portfolios. This is achieved on the one hand by using different distribution channels (branch, ATM, call center, Internet) to optimize cost allocation and respond to different consumer preferences, and on the other hand by reflecting on the bank's value chain in order to isolate the least profitable functions and identify the key functions to redeploy the bank's activities and channel its efforts towards them.

The dissemination of technological innovations in the areas of data processing and transfer is reshaping the banking business, particularly in terms of operational processes and geographic and operational boundaries. In addition, by adopting IT, banks are redefining their traditional business lines, which consist in the management of payment systems as well as the intermediation, insurance and consulting missions. Indeed, IT-based payment system management can potentially improve efficiency: on the one hand, transactional risk can be reduced by eliminating double encryption, mainly of transfers and account statements. Building up databases can also limit the risk of errors, as information is used directly from data that is generated rather than copied at each transaction. On the other hand, the ability to create files of recurring transactions over time can reduce the risk of omissions and therefore errors. In its intermediation mission, the bank can use IT in the development of new products and services. Efficiency can be improved by reducing information asymmetry. The efficiency of insurance and consulting missions can potentially be improved through the introduction of IT, particularly by reducing the time spent searching for information and by increasing the comparability of possible choices.

Moreover, with the advent of IT, banks are adopting specialization and multispecialization strategies that are conducive to a value-creation approach. Specialization is therefore a way to differentiate oneself and create added value. Concentrating skills on limited functions can generate economies of scale but inevitably leads to a breakdown of the integrated banking model. This predictably results in a disintegration of the banking value chain. All these factors lead us to move from an integrated banking model, a model characterized by the fact that a single entity is in charge of all operations, to a new model characterized by greater interaction between the various market stakeholders and greater specialization: the fragmented banking model. This model was born out of the digital technology boom that has contributed to an increasingly clear separation between production and distribution functions. Thus, the transition from the integrated model to the specialized model requires a reorganization of the banking business by re-evaluating its four functions: design, back-office, risk assessment and distribution. This new model favors a greater specialization of banking institutions.

Research by Brynjolfsson and Hitt (2000), Batt (1999), Frances, Harker and Hunter (2000) shows that IT, human capital, and decentralized work organization are all complementary variables that would promote improved productivity through better management of internal transactions in the bank. We therefore believe that investments in IT are strongly correlated with more decentralized decisions, such as those related to improving internal bank transactions. Productivity would thus be higher in banks that are able to 
combine IT investments with other organizational structures and human capital. Introducing IT in banks therefore enables them to reorganize their business in order to increasingly focus on value-creating activities.

\section{IT Impact on the Business Performance of Banks}

The most important asset that banks have is the relationship they maintain with their customers. Nevertheless, the desire to satisfy and retain the aspirations of customers to the greatest extent possible encourages banks to improve the quality of their products and services. Lamouline (1998) points out that in the banking sector, "firms innovate primarily to improve the quality of services and broaden their range of products and services". Similarly, Maloff (1996) as well as Limayem and Haloui (1997) point out that the use of IT leads to an improvement in the quality of products and services in the company. The perceived benefits of introducing IT, such as saving time, greater responsiveness, reliability and security of information exchange, offshoring, etc., can be seen as improvements in the quality of the bank's services. As a result, the more the bank adopts electronic distribution and communication channels, the more its customers present specifications by requesting high value-added customized banking services while seeking the best quality of products and services.

In addition, to meet the increased needs of customers and to create more demand, banks are expanding their product and service lines. The adoption of new electronic channels opens up new potential for the bank to expand its range of services to customers, such as image checks, electronic wallets, digital signatures, e-payment solutions, and so on. By expanding its range of products and services to meet customer requirements and needs, the bank is able to differentiate itself from its competitors and maintain or even increase its market share.

Clemons (1991) points out that IT has become a strategic necessity rather than a source of competitive advantage. Thus, as long as there are no obstacles to entry in terms of IT investments, a bank that invests in IT will not be able to increase its market share, but in refusing to invest in IT, it risks losing its market share. It is therefore in the bank's interest to invest in IT so that it can win, manage and retain new customers in foreign markets and even increase its market share in its own country by targeting new segments.

In addition, the first concern of banks is to personalize the customer relationship by creating a "tailor-made" bank. This implies the application of one-to-one marketing rules and setting up customer databases. The objective of banks is to develop behavioral patterns in order to offer banking products that are targeted and perfectly adapted to consumers' expectations which implies active collaboration of IT departments (Evans, 2000). In banks, as a result of massive investment in IT, a number of customers benefit from improved banking services through greater customization, lower transaction costs (ability to manage accounts and payments remotely), and lower search costs (access to a wider range of products). In doing so, banks move from a product-centered approach to a customer-centered approach: centralization of customer information and the exchange of information with partners including product suppliers (Teru, Idoku, \& Ndeyati, 2017).

\section{IT Impact on the Financial Performance of Banks}

Cost reduction is the main benefit of the introduction of e-business by banks. Banks use IT to lower the cost of low value-added transactions (ATM, account statements, etc.). Most studies (Riddle, 2001; Lemaître, 1997) agree that the adoption of IT leads to significant cost savings and subsequently to substantial economies of scale by offering the possibility of communicating information at a very low cost and to a very large customer base. On the other hand, in terms of banking services, the Internet offers substantial cost savings: consumers can 
reduce the cost of their banking transactions, i.e. balance inquiries, transfers, bill payments, etc. El Idrissi (2000) points out that the cost-to-income ratio (general expenses to net banking income) is 3 to 4 times lower than the average for the sector in both Europe and the United States. This could be explained, according to this author, by lower transaction costs and significant revenues. Indeed, the Internet offers very low fixed costs and, in most cases, direct transactions requiring no human intervention. According to Bernstein (2000), banks that operate online see an immediate decrease in their operating costs. Limayem and Haloui (1997), Maloff (1996) and Limayem, Poisson and Dhrif (1998) demonstrated that the use of IT within a bank has a significant impact on reducing transaction costs.

\section{Contributions of Digitalization to Banking}

Banking is the ultimate industry where digitization is likely to take off. Aware of the importance of this digital transformation as a catalyst for growth and productivity, banks will have to thoroughly adapt their business model to the changes brought about by the internationalization of markets, the advent of digital distribution channels and the change in consumer behavior in order to survive and remain competitive.

\section{Attracting and Retaining Customers through Digital Channels}

In order to meet the expectations of its customers and meet new needs, today's banks must adapt their strategies and comply with new standards (Krings, 2020). They are therefore required to meet various criteria that have now become essential for their customers: being multi-channel in order to meet their customers through the various available channels (physical, digital, nomadic, etc.), being clear-sighted about the use of new forms of available data such as Big Data, being flexible by adapting the organization and internal processes (increased efficiency through automation and "digitalization" of processes), and being socially active by improving their brand image among their customers and employees through the use of social media.

To this end, digital banks offer users several advantages, especially for users who wish to slow down their day-to-day pace and optimize their time. This close relationship opens many doors when faced with time or distance constraints that are often a hindrance for banks. Almost all banking services can now be done using the Internet, which represents significant time savings for customers. Moreover, thanks to the electronic signature, management is easier, from the opening of an account using a Smartphone, to the simulation of a loan to have a quick overview. This is a huge market share that banks would do well to keep and conquer. In addition, mobile and tablet applications, commonly referred to as "M-banking", allow banks to be in line with customer expectations. They offer them the possibility to perform the simplest operations without having to contact an agent or in a dematerialized way. The evolution of customer profiles leads to an unprecedented problem for banks: customization. Until now, banking offers were based on an overly traditional segmentation called "service", with the aim of dividing customers into distinct groups but forming a mass that remains too homogenous and undifferentiated. In order to capture interest and build customer loyalty, segmentation must be increasingly sophisticated and customized. The wealth and amount of information offered by Big Data, coupled with the assimilation of this information by account managers, is an element of response for players in the sector.

A new form of competition is also emerging in the new payment uses: NFC (Near Field Communication, Short Range Wireless Communication), mobile payment, Cloud-based payment, etc. Customers or prospects, being fond of new technologies, willingly give in to the offers of the new market players in the industry: PayPal, Square, Apple, etc. taking advantage of this new generation of mobile customers (called "mobinautes" in French). These new players, like PayPal, are already established in Europe as a credit institution. The expectations 
of these new customers and the emergence of new players in the sector are pushing banks to adopt new approaches. This transformation concerns more particularly three key areas: the optimization of the customer experience, the digital transformation of operational processes through automation and dematerialization, and the transformation of organizations.

\section{Improved Profitability}

The long journey of retail banks to respond instantly to the demands of their digital customers not only generates transformation costs, but also business opportunities and lower costs that boost their income statements. This is the conclusion of a study conducted by the Boston Consulting Group (BCG) with around 40 institutions worldwide, representing a panel of 220 million customers and about 26,300 bank branch. Moreover, a study by the consulting firm McKinsey entitled "Accelerating the digital transformation of companies: a source of growth and competitiveness for France" reveals that digital transformation gives banks advantages that outweigh the risks. Indeed, this new policy could enable banks to increase their margins by around $40 \%$. This hypothesis will become reality provided that banks manage to adopt relevant digital strategies in order to take full advantage of the opportunities offered by this transformation.

\section{Change in the Banking Profession}

Several research studies have shown that the introduction of new technologies leads to the emergence of new banking professions and a new definition of banks, their dimensions and their tasks (Audrin \& Davoine, 2017). In this innovative context, the banking profession has changed in terms of the responses to be provided to customers. As a result, bankers can more easily empower advisors and make them more autonomous. For example, they can delegate the tools used to manage the branch to advisors using performance indicators in the form of a mobile application that can be developed on the bank's tablets. In addition, digital technology will benefit agencies in reducing administrative tasks thanks to the automation of certain procedures. Bankers will therefore be able to more easily adopt their role as "coaches" in terms of optimizing the time spent using the tools made available to their sales staff.

\section{THE CHALLENGES OF BANKING BUSINESS MODELS IN THE COVID-19 ERA}

Following the 2008 crisis and with the strengthening of banking regulations, banks have faced many challenges: the need to increase their capital, improve their asset portfolios and more recently, accelerate the digitalization of their activities and internal processes. Efforts in recent years to comply with regulatory requirements and to face the threat of new entrants, especially technology companies in the financial sector (Fintechs), reduced their profitability and led them to fundamentally rethink their business model. This has led to changes in their financing model (extension of financial resources), their choice of resource allocation, their organization, their working methods and their relations with stakeholders.

The current health crisis reveals a change in their business model marked by a twofold movement: a refocusing on local financing activities and an acceleration of digital technologies applied to financial services. Hence the emergence of a new challenge: succeeding in innovation by combining the best of the human and digital worlds.

\section{Refocus on Financing Activities}

Regarding the bank's financing role, the COVID-19 crisis could accelerate the decline in the international activity of universal banks, a decline that has already begun in September 2019. As a result, bank intermediation activities, i.e., lending to small and medium-sized enterprises and mid-sized companies, are booming. The exceptional measures to support the economy are made possible by the relaxation of the countercyclical bank capital cushion (Teru, Idoko, \& 
Bello, 2019). Indeed, there is a slowdown in banking regulation with the postponement of the entry into force of the Basel III Accord. Given the current context, banks' resources are primarily allocated to financing the impacts of the pandemic triggered by the coronavirus. Thus, banks no longer play a mere financing role, but also a social role by directly assisting the State in economic recovery.

\section{Reconciling "Human and Digital" Worlds}

In the current crisis context, customer relations provide a fundamental social link well beyond simple banking transactions (Girish \& Ghosh, 2020). In this context, the empowerment and training of bank staff in digital technologies are two key factors in their business model. For several years now, digitalization has been one of the challenges facing banks due to the change in their customers' behavior. With the current crisis, banks will have to accelerate the transformation of their business model by getting closer to the Fintechs' business model, especially in terms of value proposition. In addition, the digitalization of processes (thanks to artificial intelligence, for example) remains essential to achieve productivity gains. Managing the crisis will thus require banks to make their business processes simpler, more agile, more responsive, more efficient, faster and more flexible in their response to the needs of companies and individuals.

The digitization of banking activities has already been anticipated for several years: in terms of recruitment profiles by seeking greater specialization in compliance and IT-related professions and in terms of training by creating a certification scheme built on a digital skills base for all employees in the sector. COVID-19 revealed the central role of the human factor in banking intermediation and support for the real economy, which represents a nice revenge for the so-called "traditional" banks as opposed to the pure players that are the Fintechs. By remaining close to their clients and helping them to deal with their cash flow difficulties, local bankers build trust and loyalty. Moreover, this exceptional crisis is an opportunity to accelerate the transformation of the universal banking business model. The bank of the future will need to leverage digital technologies to improve and secure the consumer experience, while strengthening its ability to advise customers who are increasingly demanding high value-added solutions.

\section{POST-COVID BANKING INDUSTRY: WHAT WOULD BE THE NEW BUSINESS MODEL?}

The COVID-19 health crisis will undoubtedly have an impact on our economy. It will become urgent for banks to rethink their business model, i.e. their very rationale. They should therefore integrate into their managerial practices "the levers of essentiality" for a more humane capitalism. An "essential" bank would be characterized by increasingly eco-systemic governance. The implementation of such governance, including the company's ecosystem, will go hand in hand with better local anchoring, which mutual companies have already integrated because of their statutes and history. One of the direct consequences would be a revitalization of the regions and the local creation of activities and jobs.

Moreover, under the pressure of financial performance, new technologies have so far been perceived as productivity drivers, generating staff reductions. Tomorrow, there will be a real challenge to imagine how these technologies could create value for humanity. Knowing how to redefine the human-machine mix will be a priority. The lockdown will have made it possible to test and fully experience remote relationships, while educating the most reluctant. Companies should learn from these practices and initiate phases of industrialization of this mass telework experience. However, this period of restricted social links is likely to feed frustrations for the physical relationship, since humans, by definition, are social animals. 
Restoring the place of the human being, whether in customer relations, in the branches, or in the bank, will certainly be a challenge that will create emotions and jobs!

Therefore, aligning the company's values with its managerial practices has become essential. Increasingly aware of the reality of life, employees will no longer accept being fed with marketing and communication slogans aiming to advocate good corporate values while they are not followed in day-to-day practices. Managing will result in the need to develop a corporate vision, embodied by the managers, to embark employees through individual responsibility and recognition of initiative and to support the development of individuals and their skills. Finally, this crisis could also be a catalyst for accelerating awareness of the climate emergency and its impact on the environment. A real transition in terms of ecoconsumption and environmentally-friendly conduct within the company and among its stakeholders would finally be initiated. Banks will not only be concerned with their own carbon footprint, but also that of their customers or suppliers.

As for the relationship between COVID-19 and digitization, it appears that the pandemic has given a tremendous boost to the development of digitization around the world. Ben Romdhane (2020) underlined in this context that "COVID-19 could serve as a trigger for a sustainable digital transformation!" We must recognize the merit and the important role of Fintechs in the development of the digitization of financial services well before the pandemic. The great capacity for innovation and the responsiveness of these start-ups have shaken even the largest and most conservative financial institutions, pushing them to reflect on their digital (transformation) strategy to follow and respond to changes in their customers' consumption patterns, whether individuals or professionals. However, the general or partial shutdown induced by the COVID-19 pandemic has led some financial institutions to accelerate their digital transformation and others to undertake a plan of digital transformation and development of digital financial services. In the context of the health crisis, several governments have relied on digital technologies and in particular on mobile phones to distribute financial aid to households and entrepreneurs, relying among other things on the financial sector and its digital solutions.

Digital finance will develop further after the COVID-19 crisis thanks also to the various steps that financial regulators and supervisors are increasingly taking to make the supply of digital financial services easier and more flexible. In addition, regulators have an important role in this drive, and the COVID-19 pandemic has made them aware of the need to keep pace with new technologies and help meet the expectations of citizens and consumers. In this process of digitizing financial services, speed should not be confused with haste, and the fundamental objectives should not be lost sight of. In fact, and given the importance of the human and financial resources to be committed to this type of strategic project, this transformation must be a success and must generate added value for all stakeholders, and primarily customers/consumers. Moreover, digitalization is not an end in itself. It must meet the expectations of the customers and the financial inclusion of populations and entrepreneurs.

\section{CONCLUSION}

The birth of information technology several decades ago has considerably changed the functioning and strategies of the banking sector. In particular, the digitalization of financial services has dramatically changed the banking business and has led the bank to completely overhaul its operating methods and its vision of customer relations. The current COVID-19 health crisis reveals a change in the business model of banks marked by a twofold movement: a refocusing on local financing activities and an acceleration of digital technologies applied to financial services. Hence the emergence of a new challenge: succeeding in innovation by combining the best of the human and digital worlds. Aware of the importance of the digital transformation as a catalyst for growth and productivity, banks must thoroughly adapt their 
business model to the changes brought about by the internationalization of markets, the advent of digital distribution channels and the changes in consumer behavior in order to survive and remain competitive. Digitization could be the solution for banks that are always trying to mitigate risk. This health crisis could accelerate their digital transformation while maintaining their traditional role. Through this digital transformation and their ability to reinvent themselves, banks would be able to protect themselves against possible crises similar to the current one. By adopting a more digital and more open behavior, banks would be immune to such crises because they have contingency strategic plans, because they are better equipped to counter threats and are therefore better prepared to transform them into opportunities.

\section{REFERENCES}

Audrin, B., \& Davoine, E. (2017). The HR function in the face of the digitalization of organizations: The case of digital communications tools. Management \& Future, 92(2), 15.

Batt, R. (1999). Work Organization, Technology and Performance in Customer Service and Sales. Industrial and Labor Relations Review, 52(4), 539-564.

Ben Romdhane, S. (2016). Impact of Information Technologies on Banking Performance. European University Editions, 465 pages.

Ben Romdhane, S. (2020). Tunisia in the Light of COVID-19: Technology Comes to the Rescue. International Journal of Managerial Studies and Research, 8(10), 63-64.

Bernstein, R. (2000). B-to-B companies go online as a matter of survival. Active Media Research.

Brynjolfsson, E., \& Hitt, L. (2000). Beyond computation: information technology, organizational transformation and business performance. Journal of Economic Perspectives, 14(4), 23-48.

Clemons, E.K. (1991). Evaluation of strategic investments in information technology. Communication of the ACM, 34, 1-23.

Drucker, P. (1988). The Coming of the New Organization. Harvard Business Review, 66(1), 45-53.

El Idrissi, A. (2000). The influence of information and communication technologies on the structures and functioning of banks. Conference : Corporate communication, crossed perspectives, Management sciences-Communication Sciences, December 6 and 7, Nice (Conference proceedings), 194-202.

Evans, B. (2000). E-commerce: Reality Bites. Information Week Online, 5 June.

Frances, Z., Harker, P.T., \& Hunter, L.W. (2000). Inside the Black Box: What Makes a Bank Efficient?. In Patrick T. Harker and Stayios A. Zenios, eds, The Performance of Financial Institutions, Cambridge: Cambridge University Press. 
Girish, G.P, \& Ghosh, S. (2020). Dynamics between Digital Visibility through Social Media Marketing and Crowdfunding: Path to Succeed in Entrepreneurship. Indian Journal of Finance and Banking, 4(2), 28-37.

Krings, W. (2020). Impacting the B2B-Business Development Process: Social Media Usage within a Global Software Environment. International Journal of Accounting \& Finance Review, 5(1), 1-11.

Lahittete, M. (1999). Does the use of ICT reduce the costs of organizations? Doctoral studies from the GDR TIC and Society, January 28-29.

Lamouline, O. (1998). Technological innovation in credit institutions and insurance companies. SESSI, 95, November. Retrieved from www.industrie.gouv.fr

Laudon, K.C., \& Laudon, J.P. (2006). Information system management. $9^{\text {th }}$ Edition Eric Fimbel, Pearson Education, France, 638 pages.

Lemaître, P. (1997). The challenges of remote banking. Banque, 587, 63-65.

Lemarque, P. (1999). The key activities of the banking professions : An analysis by the value chain. Finance Control Strategy, 2, 135-158.

Limayem, M., \& Haloui, N. (1997). The Impact of Information Technology Investment on Business Performance: A New Vision. FSA working document, University of Laval 8.

Limayem, M., Poisson, M.A., \& Dhrif, H. (1998). Impact of Internet use on organizational performance. FSA working document, University of Laval 8.

Maloff, J. (1996). Measuring the Value of the Internet for Business. in Cronin M.J., The Internet Strategy Handook, Harvard Business School Press.

Malone, T. (1997). Modeling coordination in organizations and markets. Working paper, Sloan School of Management.

Morris, T. (1986). Innovation in banking. RLE (Banking and Finance), $1^{\text {st }}$ Edition, London, 148 pages.

Porter, M. E. (1980). Competitive strategy: techniques for analyzing industries and competition. New York, Free Press.

Porter, M. E., \& Millar, V. (1985). How information gives you competitive advantage. Harvard Business Review, 63(4), 149-160.

Quintas, P. (1991). Engineering solutions to software problems: some institutional and social factors affecting change. Technology analysis and Strategic Management, 3, 359-376.

Reix, R. (1998). Information Systems and Management of Organizations. $2^{\text {nd }}$ Edition, Vuibert Management, Paris, 405 pages. 
Riddle, D.I. (2001). Business Case Framework for E-Business Adoption in Small Banks. Business Case Framework, Foundation of Canadian Woman Entrepreneurs, 1-38.

Roman, B., \& Tchibozo, A. (2017). Transforming banking: Banking strategies in the digital age. Dunod Editions, 2017.

Selase, A. M., \& Selase, A. E. (2019). The Pros and Cons of Adopting Technology as a Business Pilot: Global Perspective. Indian Journal of Finance and Banking, 3(2), 1-4.

Teru, S. P., Idoko, I. F., \& Bello, L. (2019). The Impact of E - Accounting in Modern Businesses. International Journal of Accounting \& Finance Review, 4(2), 1-4.

Teru, S. P., Idoku, I., \& Ndeyati, J. T. (2017). A Review of the Impact of Accounting Information System for Effective Internal Control on Firm Performance. Indian Journal of Finance and Banking, 1(2), 52-59.

Venkatraman, N. (1995). Business reconfigurations brought about by information technology. in The competitive business of the future. Scott Morton M.S. (Ed.). Paris, Organizational Editions.

\section{Copyrights}

Copyright for this article is retained by the author(s), with first publication rights granted to the journal. This is an open-access article distributed under the terms and conditions of the Creative Commons Attribution license (http://creativecommons.org/licenses/by/4.0/). 